\title{
Research \\ Quantifying Biodiversity for Building Resilience for Food Security in Urban Landscapes: Getting Down to Business
}

\author{
$\underline{\AA \text { As a Jansson and Steven Polasky }}{ }^{1}$
}

\begin{abstract}
A steady stream of ecosystem services is essential for human welfare and survival, and it has been convincingly shown that these flows are being eroded. Compelling theoretical knowledge about essential connections between ecosystem service generation, biodiversity, and resilience in socialecological systems already exists; however, we still, to a great extent, lack spatially explicit quantitative assessments for translating this theoretical knowledge into practice. We propose an approach for measuring the change in flow and resilience of a regulating ecosystem service on a landscape scale over time when the landscape is exposed to both land use change due to urban expansion, and change in a large-scale economic driver. Our results quantitatively show that there can be a substantial decrease in resilience due to negative effects on response diversity without detecting any major decrease in ecosystem service generation over time, thus generating a sense of false security and sustainability.
\end{abstract}

Key Words: ecosystem services; food security; functional diversity; pollination; resilience; response diversity; urban ecology

\section{INTRODUCTION}

Ecosystem services provide the basis for human well-being and survival. The findings of the Millennium Ecosystem Assessment (MA), an international attempt at measuring the state of ecosystems worldwide, show that more than $60 \%$ of the assessed ecosystem services are being eroded (WRI 2005). Despite the obvious connections between ecosystem services and well-being, it has proven difficult to translate the importance of maintaining the flow of ecosystem services into tangible and credible estimates of the value of these services (although see NRC 2005, WRI 2005). Spatially explicit quantitative assessments are crucial in this context, but are still lacking (Balmford et al. 2002, WRI 2005). However, to be useful over time, such assessments also need to take into account that we live in a world of change (Rockström et al. 2009). The profound effects of climate change (IPCC 2007) and the global economic crisis of late (FAO 2008) are striking examples. We need to explicitly assess how to build, maintain, and increase the resilience of our socialecological systems to ensure the generation of ecosystem services into the future. In this paper, we define resilience as the capacity of a system to experience shocks while retaining essentially the same functions, structure, feedbacks, and therefore identity (Walker et al. 2006). These systems also exhibit thresholds that, when exceeded, result in changed system feedbacks that lead to changes in function and structure. In such cases, the system is said to have undergone a regime shift (e.g., Scheffer et al. 2001).

The significance of biodiversity in this context has been extensively discussed (WRI 2005, Balvanera et al. 2006). The functional aspect of biodiversity, that is, the identity, abundance, and range of species traits, appears to be considerably more important than species number in determining the effects of biodiversity on many ecosystem services (Hooper et al. 2005, Diaz et al. 2007). Biodiversity supplies the species and the variety of traits needed for maintaining functions for ecosystem services generation. However, the upholding of the different functions over time cannot be taken for granted. A decline in biodiversity can lead to a decline in ecosystem services generation, sometimes in a dramatic fashion, unless alternative species are available. The existence and use of ecological 
thresholds as a conceptual basis for developing tools to conserve and sustainably manage natural resources is essential in this context (Huggett 2005). Thus, building on the notion of redundancy (Walker 1992), sustaining diversity within functional groups is important. This aspect of biodiversity, referred to as response diversity, has been far less investigated (although see Nyström 2006), and is a critical element in building resilience (Elmqvist et al. 2003).

Today, most of the human population on the planet, including $75 \%$ of Europeans, lives in urban areas (EEA 2006). Due to the growing pressure on and demand for land for urban growth, a focus on the generation of ecosystem services in the context of urban development and management is important (see e.g., McDonald 2008). The ecosystem service of pollination is relevant in this context because urban land use likely will have a large effect on terrestrial ecosystems in this century (Sala et al. 2000), and the resulting habitat fragmentation is considered to be a major threat to wild pollinators (Allen-Wardell et al. 1998). More than $75 \%$ of the world's crop plants and many species that are the base for plant-derived pharmaceuticals rely on pollination by animal vectors. In a recent review of the importance of pollinators in changing landscapes for world crops, Klein et al. (2007) state that of 107 important crops, pollination is essential for 13 , highly important for 30 , and moderately important for 27 . Among the pollinator-dependant crop plants are different types of oil rapeseed like Canola, an important crop worldwide (SCDC 2008). For some types of rapeseed lines, the seed weight per plant has been shown to increase by more than $80 \%$ due to pollination (Steffan-Dewenter 2003).

The MA goal of eradicating extreme poverty and hunger (UN 2008) is also relevant in an urban context because many city inhabitants depend on food from green areas within the urban area (Smith 1996). The informal production of food in city areas is often referred to as urban agriculture and is a widespread strategy adopted by urban dwellers in many cities worldwide (see e.g., Ashebir et al. 2007). Upholding the ability to grow food within and in the vicinity of urban areas in the face of change is thus a valid argument for ensuring the existence of the pollination service.

In the context of growing cities and change, there is an urgent need to operationalize our understanding of the links between loss of biodiversity and loss of important ecosystem services. In this study, we attempted to address some of those links by connecting the work of wild bees through the regulating ecosystem service of pollination to the provisioning service of crop generation. In order to investigate the change in the pollination potential over time, and the resulting change in crop output, we attempted to (i) quantify the effect of urban land use change in a spatial landscape context when implementing an urban development plan in combination with a change in crop choice based on change in global economic food market prices, and on switching from a pollinated to a non-pollinated crop. We also attempted to (ii) quantify the difference in impact on the pollination service when looking at a lumped functional group and a specific subfunctional group. Furthermore, we assessed (iii) a second amplified urban development scenario to better match the urbanization pace of other European cities of similar size. Finally, we discuss the results in the context of response diversity, sustainable urban development, and food security.

\section{METHODS}

\section{Study area}

Stockholm County (Fig. 1), with its 1.9 million inhabitants, generates one-third of the economic growth of Sweden. The county covers about 6500 $\mathrm{km}^{2}$. About $5 \%$ of the urban agriculture landscape of Stockholm County is devoted to growing oil rapeseed. Although the arable land used for growing oil rapeseed at present is relatively small compared to other crops, there are still some hundred oil rapeseed fields in the landscape that require pollination (Fig. 1).

\section{Urban development scenarios}

\section{The regional urban development scenario}

There are major challenges awaiting the city of Stockholm through pending urban expansion. The potential spatial expansion of the area is presented in the Regional Urban Development Plan (RUDP) (RUFS 2001). However, although a $25 \%$ increase 
Fig. 1. The Stockholm County, Sweden. The blue dots show the location of all oil rapeseed fields in the county in 2006 (Svenska Raps 2007).

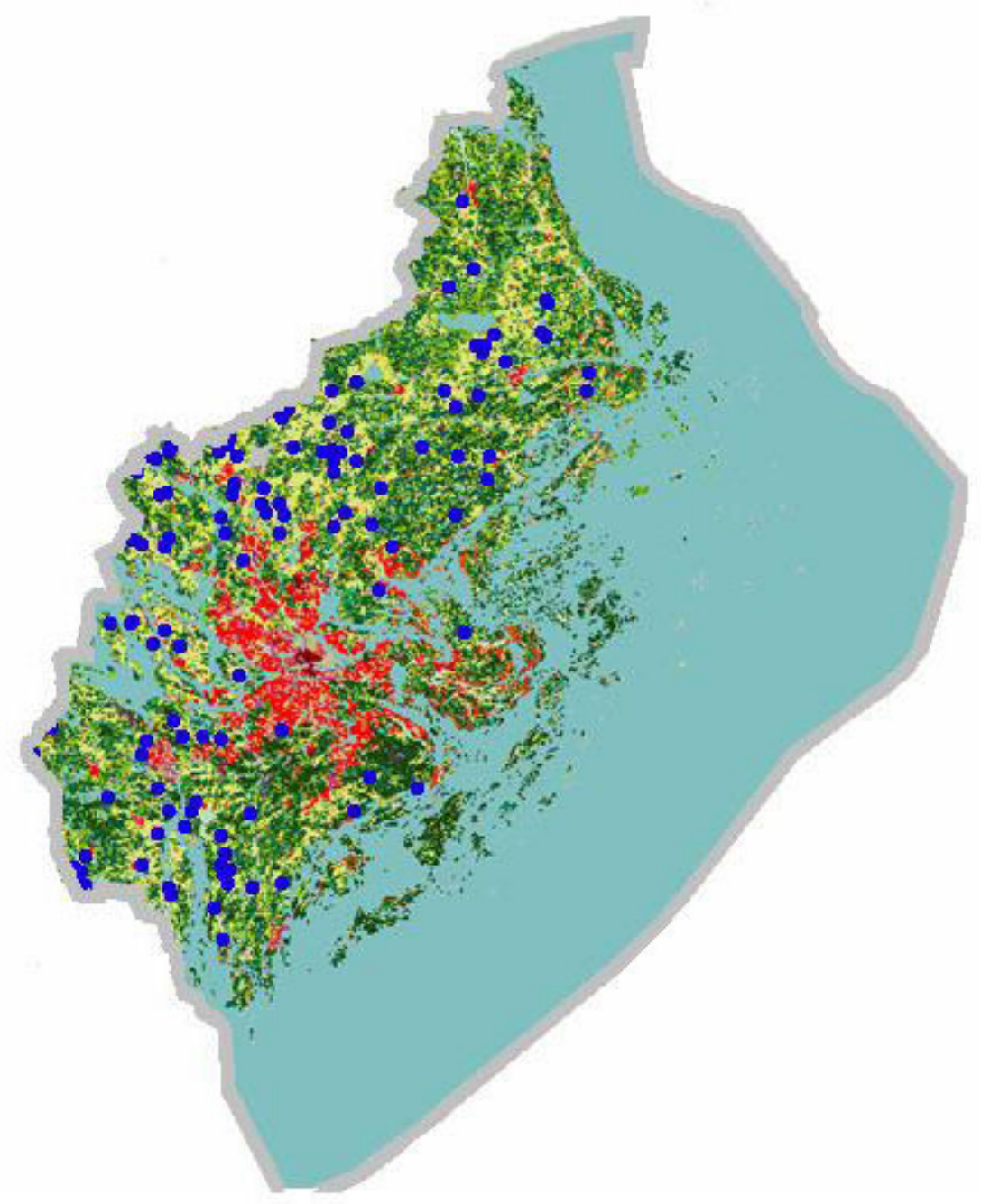

in population by the year 2030 has been projected, there are already signs of exceeding that projection (RUFS 2010). To compensate for this and to give the results broader relevance in a more general context, an additional RUDP scenario that amplifies the effects of the RUDP by $50 \%$ has also been assessed to better match the predicted rates of change in other cities in Europe (ESPON 2009). All areas affected by the land use change brought about by the RUDP will thus, in this second RUDP scenario, experience a $50 \%$ transformation of seminatural areas into urban area.
The non-pollinated crop scenario

Through the quantification of the effect of urban development on response diversity, the role of biodiversity in building resilience is partly addressed. However, it is just as important to acknowledge the social context within which the resilience building process is taking place (Berkes and Folke 1998). Social and economic drivers are important not only for generating pragmatic strategies for moving down a desired path of development, but also for generating constructive 
scenarios of change (Costanza et al. 2007). The impacts on a region, such as Stockholm County, are potentially strongly influenced by large-scale social drivers such as food market prices (FAO 2008), pending migration due to climate change (IPCC 2007), or institutional change driven by, for example, international agreements to optimize collective action, like the Kyoto protocol. This is especially true for urban systems because the socioeconomic links to the generation of ecosystem services in those systems are most strongly expressed at a regional and global scale abstracted through the market (Deutsch et al. 2003). Thus, although population increase, as expressed in the RUDP scenario, will influence urban land use change, external socioeconomic drivers, like future demands for different crops, can also potentially have an impact, which may drastically change present land use priorities (IPCC 2007). For example, during 2008, global food prices rose at an unprecedented rate and created severe consequences for the world's poorest countries (FAO 2008). Part of the increase in food prices was due to a switch to biofuels (like canola), which has pulled land out of food production (FAOSTAT 2008). With such drastic changes fresh in mind, it is feasible to make a shift away from growing mass flowering crops for biofuel production to, for example, growing wheat to meet a potentially pending food shortage. To assess the effect on pollination potential of switching from oil rapeseed to wheat production in all oil rapeseed fields in Stockholm County, the nonpollinated crop (NPC) scenario was envisioned. When this scenario is implemented, all wild bee pollinators in the functional group would then depend on semi-natural habitats for nesting as well as forage resources instead of being correlated with mass flowering crops (Corbet 2000). The seminatural habitat classification of the study builds on Steffan-Dewenter et al. (2002) but was also expanded and modified (Table 1). This scenario provides the opportunity to assess the potential to return to pollinated crops in the future - i.e., to quantify the change in resilience of the landscape through change in response diversity in the pollinator functional group.

\section{The pollinators}

The pollinators that provide the major part of the pollination service at present are short- tongued generalist bumblebees (Walter-Hellvig and Frankl 2000, Steffan-Dewenter 2002). These species are relatively insensitive to land use change as long as small parts of the landscape are available for nesting and there is an abundance of mass flowering crops (see e.g., Maler et al. 2008). The strongest correlation between the proportion of mass flowering crops and bumblebee densities has been found for landscape sectors with a 3000-m radius (Westphal et al. 2003). Many solitary bees also have the potential to pollinate oil rapeseed (Pettersson et al. 2004), and can therefore be included in the same functional group, albeit they are not identical in their function. They are thus potentially contributing to the resilience of the landscape by increasing response diversity. Without any mass flowering crops, the wild bee pollinators are correlated to the percentage of semi-natural habitats in the landscape. The strongest correlation between proportion of semi-natural habitats and wild bees in general occurs at an operational scale of $750 \mathrm{~m}$ (SteffanDewenter et al. 2002) (Fig. 2). Because solitary wild bees, when studied separately from the lumped wild pollinator group, have been shown to operate on a different scale (Fig. 3), the effect of land use change on these types of pollinators is potentially different.

\section{Implementing the Regional Urban Development Plan and non-pollinated crop scenario}

Change in lumped wild bee pollinators

After implementing the NPC scenario, the pollinators in the lumped wild bee functional group, including both generalists and specialists, will rely on semi-natural habitats for both feeding and nesting purposes according to "Eq. 1" (based on Steffan-Dewenter et al. 2002):

$$
\ln \boldsymbol{y}_{a j t}=-0.40+0.0748 \cdot \arcsin \sqrt{\boldsymbol{x}_{a j t}}
$$

The equation describes the relationship between the number of flower-visiting bees per $15 \mathrm{~min}$ and the proportion of semi-natural habitats where $a$ refers to the lumped wild bee functional group, $X_{a i t}$ is the percent of semi-natural habitat within a circle with a 750-m radius at parcel $j$, and $Y_{a j t}$ is the number of lumped wild bees per square meter in the circle. We evaluated the number of bees with the current landscape $(t=0)$ and the future landscape $(t=1)$. 
Table 1. Classified semi-natural land use types derived from the Swedish CORINE land use and vegetation database (2006), based on Steffan-Dewenter et al. (2002).

Discontinuous urban fabric with more than 200 inhabitants and major areas of gardens and greenery

$30-50 \%$ made up of built-up areas. Remaining area made up of green areas not defined as urban green areas

Discontinuous urban fabric with less than 200 inhabitants

Urban green areas

Solitary houses with property

Road and rail networks and associated land

Airfields

Golf courses $\dagger$

Non-urban parks

Camping sites and holiday cottage sites

Pastures

$\dagger$ Based on Gange and Lindsay 2002
Built-up areas outside densely populated urban areas. 30$80 \%$ made up of built-up areas. Remaining area made up of vegetation

Green areas within major populated centers where $70 \%$ of the area is vegetated. Includes parks, cemeteries, allotment areas, botanical gardens, amusement parks, forest areas, and zoological gardens

Groups of houses or solitary houses with associated gardens and large open land

Includes all major roads, roads and railroads and associated land such as roundabouts, verges, embankments, and lay-bys

Runway on grass

Golf courses and associated buildings

Park areas such as amusement parks, parks around castles and mansions, and major cemeteries outside of major population centers

Includes trailer parks

Grass areas used for pasture or haymaking. Not part of rotation farming practices 
Fig. 2. Scale of operation of the lumped wild bee pollinator group, i.e. solitary bees and generalists together.

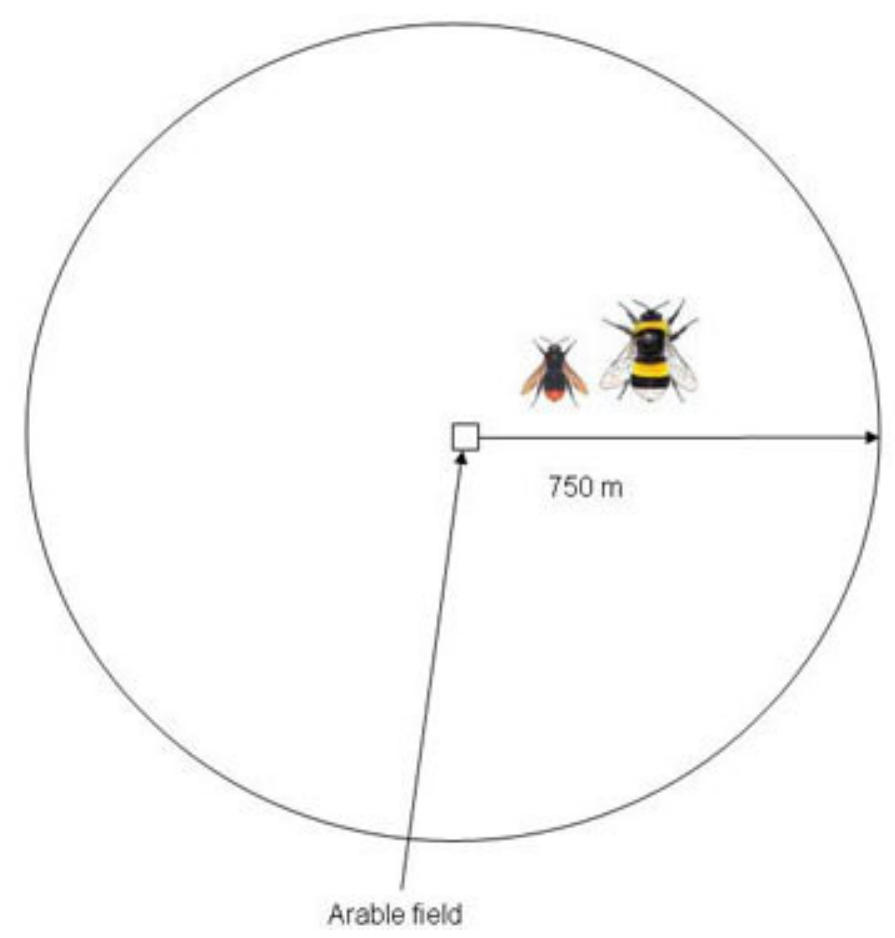

Change in solitary wild bees

The solitary bees correlate to the percentage of seminatural habitats with the highest correlation within a circle with a 250-m radius according to "Eq. 2" (based on Steffan-Dewenter et al. 2002):

$$
\sqrt{\boldsymbol{y}_{b j t}}=0.641+0.038 \cdot \arcsin \sqrt{\boldsymbol{x}_{b j t}}
$$

where $b$ refers to the solitary bees, $X_{b j t}$ is the percentage of semi-natural habitat, and $Y_{b j t}$ is the number of solitary bees per square meter in the circle. As for the lumped pollinator group, we then evaluated the number of solitary bees with the current landscape $(t=0)$ and the future landscape $(t=1)$.

The fractional change in total number of wild bee $\left(Y_{\text {atot }}\right)$ and solitary bee pollinators $\left(Y_{b t o t}\right)$ under the urban development scenario was calculated by summing over all parcels on the landscape $(j=1,2 \ldots$. $\mathrm{N}$ ) according to "Eq. 3" and "Eq.4":

$$
\Delta Y_{\text {atot }}=\frac{\sum_{j=1}^{N} Y_{a j 1}-\sum_{j=1}^{N} Y_{a j 0}}{\sum_{j=1}^{N} Y_{a j 0}}
$$

$$
\Delta Y_{b t o t}=\frac{\sum_{j=1}^{N} Y_{b j 1}-\sum_{j=1}^{N} Y_{b j 0}}{\sum_{j=1}^{N} Y_{b j 0}}
$$


Fig. 3. Scale of operation of solitary bees and wild bee generalists when presented separately.

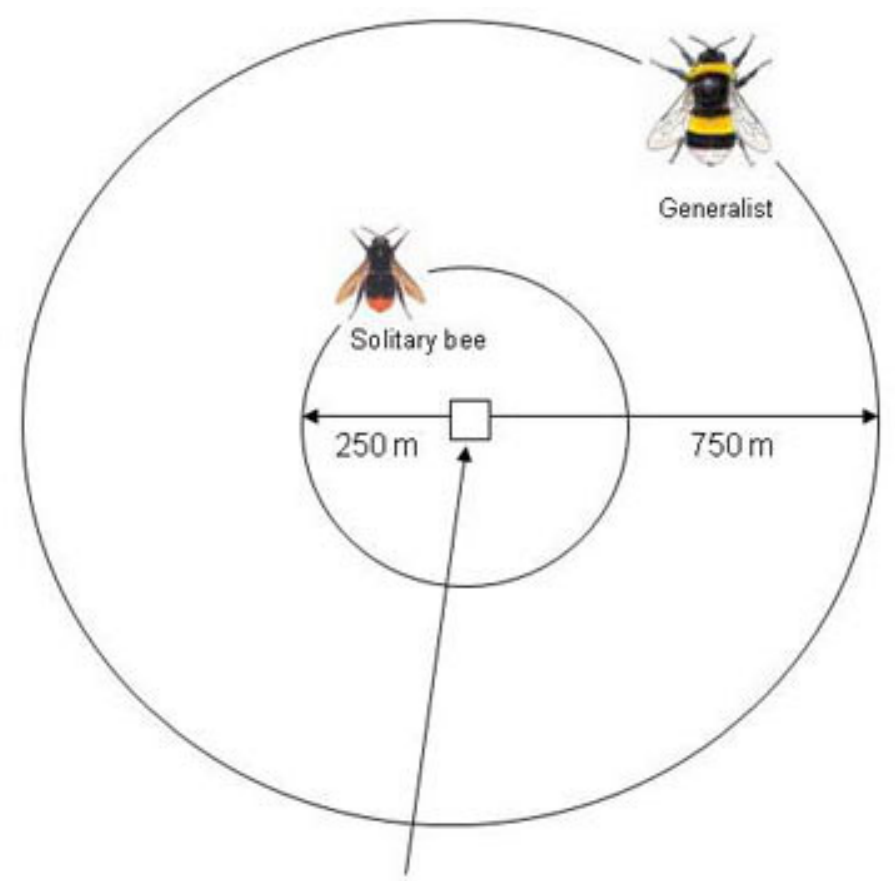

Arable field

\section{RESULTS}

Of the 192 areas where, according to the NPC scenario, there used to be an oil rapeseed field, 51 were affected by the RUDP, i.e., there was a change in land use within the $750-\mathrm{m}$ radius and/or $250-\mathrm{m}$ radius circles surrounding the areas of the former oil rapeseed fields.

\section{Implementing the Regional Urban Development Plan and non-pollinated crop scenarios}

Implementing the RUDP scenario resulted in a decrease in the semi-natural land use type within 17 of the 51 affected circles with a 750-m radius and 9 of the 250-m radius circles (Table 2). The decrease in pollination potential for the lumped wild pollinator under the RUDP and NPC scenarios was estimated at $0.66 \%$ and $0.77 \%$, respectively, for solitary bees only. The amplified RUDP scenario resulted in a decrease in the semi-natural land use type in all 51 circles with a $750-\mathrm{m}$ radius and in 39 of the 250-m radius circles (Table 3 ). The decrease in pollination potential for lumped wild bees under the amplified RUDP and the NPC scenarios was estimated at $1.34 \%$ and $1.88 \%$, respectively, for the solitary bees.

\section{Differences in impact}

The difference in impact of urbanization on pollination potential between the lumped pollinator group and the solitary bee group was 0.12 in the RUDP scenario and 0.53 in the amplified RUDP scenario. Thus, there is an increased impact on the solitary bee group in the amplified scenario by a factor 4.4 compared to the difference between the two pollinator groups in the RUDP scenario (Fig. 4). 
Table 2. Number of bees per square meter before $(t=0)$ and after $(t=1)$ the implementation of the Regional Urban Development Plan (RUDP) under the non-pollinated crop scenario. "Lumped bees" indicates both generalists and solitary bees together in the functional group.

\begin{tabular}{|c|c|c|c|c|}
\hline \multirow[b]{3}{*}{ Field No. } & \multicolumn{4}{|c|}{ RUDP } \\
\hline & \multicolumn{2}{|c|}{ Lumped bees } & \multicolumn{2}{|c|}{ Solitary bees } \\
\hline & $Y_{\text {aj0 }}$ & $Y_{\text {aj1 }}$ & $Y_{b j 0}$ & $Y_{b j 1}$ \\
\hline 1 & 0,705 & 0,703 & 0,437 & 0,437 \\
\hline 2 & 0,695 & 0,695 & 0,450 & 0,450 \\
\hline 3 & 0,691 & 0,691 & 0,430 & 0,430 \\
\hline 4 & 0,721 & 0,676 & 0,463 & 0,411 \\
\hline 5 & 0,684 & 0,684 & 0,429 & 0,429 \\
\hline 6 & 0,693 & 0,693 & 0,434 & 0,434 \\
\hline 7 & 0,691 & 0,691 & 0,423 & 0,423 \\
\hline 8 & 0,688 & 0,682 & 0,411 & 0,411 \\
\hline 9 & 0,708 & 0,708 & 0,435 & 0,435 \\
\hline 10 & 0,688 & 0,688 & 0,437 & 0,437 \\
\hline 11 & 0,692 & 0,692 & 0,426 & 0,426 \\
\hline 12 & 0,691 & 0,691 & 0,432 & 0,432 \\
\hline 13 & 0,682 & 0,682 & 0,427 & 0,427 \\
\hline 14 & 0,682 & 0,682 & 0,432 & 0,432 \\
\hline 15 & 0,690 & 0,690 & 0,430 & 0,430 \\
\hline 16 & 0,685 & 0,685 & 0,435 & 0,435 \\
\hline 17 & 0,683 & 0,681 & 0,427 & 0,411 \\
\hline 18 & 0,678 & 0,678 & 0,428 & 0,428 \\
\hline 19 & 0,688 & 0,688 & 0,411 & 0,411 \\
\hline 20 & 0.681 & 0.676 & 0,411 & 0,411 \\
\hline 21 & 0,692 & 0,692 & 0,444 & 0,444 \\
\hline 22 & 0,704 & 0,676 & 0,433 & 0,411 \\
\hline 23 & 0,696 & 0,681 & 0,411 & 0,411 \\
\hline
\end{tabular}




\begin{tabular}{|c|c|c|c|c|}
\hline 24 & 0,689 & 0,689 & 0,426 & 0,426 \\
\hline 25 & 0,682 & 0,682 & 0,411 & 0,411 \\
\hline 26 & 0,711 & 0,710 & 0,471 & 0,471 \\
\hline 27 & 0,692 & 0,692 & 0,441 & 0,441 \\
\hline 28 & 0,686 & 0,686 & 0,421 & 0,421 \\
\hline 29 & 0,689 & 0,689 & 0,454 & 0,454 \\
\hline 30 & 0,678 & 0,678 & 0,432 & 0,432 \\
\hline 31 & 0,685 & 0,685 & 0,411 & 0,411 \\
\hline 32 & 0,698 & 0,681 & 0,436 & 0,431 \\
\hline 33 & 0,696 & 0,680 & 0,425 & 0,414 \\
\hline 34 & 0,685 & 0,676 & 0,427 & 0,425 \\
\hline 35 & 0,686 & 0,686 & 0,436 & 0,436 \\
\hline 36 & 0,687 & 0,687 & 0,427 & 0,427 \\
\hline 37 & 0,687 & 0,687 & 0,411 & 0,411 \\
\hline 38 & 0,683 & 0,683 & 0,411 & 0,411 \\
\hline 39 & 0,687 & 0,687 & 0,434 & 0,434 \\
\hline 40 & 0,688 & 0,688 & 0,420 & 0,420 \\
\hline 41 & 0,681 & 0,676 & 0,411 & 0,411 \\
\hline 42 & 0,713 & 0,695 & 0,449 & 0,424 \\
\hline 43 & 0,693 & 0,689 & 0,431 & 0,426 \\
\hline 44 & 0,680 & 0,680 & 0,428 & 0,428 \\
\hline 45 & 0,681 & 0,681 & 0,434 & 0,434 \\
\hline 46 & 0,690 & 0,677 & 0,411 & 0,411 \\
\hline 47 & 0,713 & 0,676 & 0,442 & 0,411 \\
\hline 48 & 0,683 & 0,675 & 0,411 & 0,411 \\
\hline 49 & 0,683 & 0,683 & 0,411 & 0,411 \\
\hline 50 & 0,682 & 0,682 & 0,432 & 0,432 \\
\hline 51 & 0,686 & 0,685 & 0,432 & 0,432 \\
\hline
\end{tabular}


Table 3. Number of bees per square meter before $(t=0)$ and after $(t=1)$ the implementation of the amplified Regional Urban Development Plan (RUDP) under the non-pollinated crop scenario.

\begin{tabular}{|c|c|c|c|c|}
\hline \multirow[b]{3}{*}{ Field } & \multicolumn{4}{|c|}{ RUDP amplified } \\
\hline & \multicolumn{2}{|c|}{ Lumped bees } & \multicolumn{2}{|c|}{ Solitary bees } \\
\hline & $\mathrm{Y}_{\mathrm{aj} 0}$ & $Y_{a j 1}$ & $Y_{b j 0}$ & $Y_{b j 1}$ \\
\hline 1 & 0,705 & 0,692 & 0,437 & 0,429 \\
\hline 2 & 0,695 & 0,687 & 0,450 & 0,437 \\
\hline 3 & 0,691 & 0,684 & 0,430 & 0,424 \\
\hline 4 & 0,721 & 0,674 & 0,463 & 0,411 \\
\hline 5 & 0,684 & 0,680 & 0,429 & 0,424 \\
\hline 6 & 0,693 & 0,686 & 0,434 & 0,427 \\
\hline 7 & 0,691 & 0,685 & 0,423 & 0,419 \\
\hline 8 & 0,688 & 0,678 & 0,411 & 0,411 \\
\hline 9 & 0,708 & 0,695 & 0,435 & 0,428 \\
\hline 10 & 0,688 & 0,683 & 0,437 & 0,429 \\
\hline 11 & 0,692 & 0,686 & 0,426 & 0,421 \\
\hline 12 & 0,691 & 0,685 & 0,432 & 0,426 \\
\hline 13 & 0,682 & 0,678 & 0,427 & 0,422 \\
\hline 14 & 0,682 & 0,679 & 0,432 & 0,425 \\
\hline 15 & 0,690 & 0,684 & 0,430 & 0,424 \\
\hline 16 & 0,685 & 0,681 & 0,435 & 0,428 \\
\hline 17 & 0,683 & 0,678 & 0,427 & 0,411 \\
\hline 18 & 0,678 & 0,675 & 0,428 & 0,423 \\
\hline 19 & 0,688 & 0,682 & 0,411 & 0,411 \\
\hline 20 & 0,681 & 0,675 & 0,411 & 0,411 \\
\hline 21 & 0,692 & 0,686 & 0,444 & 0,433 \\
\hline 22 & 0,704 & 0,674 & 0,433 & 0,411 \\
\hline 23 & 0,696 & 0,678 & 0,411 & 0,411 \\
\hline
\end{tabular}




\begin{tabular}{|c|c|c|c|c|}
\hline 24 & 0,689 & 0,683 & 0,426 & 0,421 \\
\hline 25 & 0,682 & 0,679 & 0,411 & 0,411 \\
\hline 26 & 0,711 & 0,697 & 0,471 & 0,447 \\
\hline 27 & 0,692 & 0,685 & 0,441 & 0,432 \\
\hline 28 & 0,686 & 0,681 & 0,421 & 0,418 \\
\hline 29 & 0,689 & 0,683 & 0,454 & 0,439 \\
\hline 30 & 0,678 & 0,676 & 0,432 & 0,426 \\
\hline 31 & 0,685 & 0,681 & 0,411 & 0,411 \\
\hline 32 & 0,698 & 0,678 & 0,436 & 0,425 \\
\hline 33 & 0,696 & 0,677 & 0,425 & 0,413 \\
\hline 34 & 0,685 & 0,675 & 0,427 & 0,421 \\
\hline 35 & 0,686 & 0,681 & 0,436 & 0,428 \\
\hline 36 & 0,687 & 0,682 & 0,427 & 0,422 \\
\hline 37 & 0,687 & 0,682 & 0,411 & 0,411 \\
\hline 38 & 0,683 & 0,679 & 0,411 & 0,411 \\
\hline 39 & 0,687 & 0,682 & 0,434 & 0,427 \\
\hline 40 & 0,688 & 0,683 & 0,420 & 0,418 \\
\hline 41 & 0,681 & 0,675 & 0,411 & 0,411 \\
\hline 42 & 0,713 & 0,688 & 0,449 & 0,420 \\
\hline 43 & 0,693 & 0,683 & 0,431 & 0,422 \\
\hline 44 & 0,680 & 0,677 & 0,428 & 0,423 \\
\hline 45 & 0,681 & 0,678 & 0,434 & 0,427 \\
\hline 46 & 0,690 & 0,675 & 0,411 & 0,411 \\
\hline 47 & 0,713 & 0,675 & 0,442 & 0,411 \\
\hline 48 & 0,683 & 0,673 & 0,411 & 0,411 \\
\hline 49 & 0,683 & 0,680 & 0,411 & 0,411 \\
\hline 50 & 0,682 & 0,679 & 0,432 & 0,426 \\
\hline 51 & 0,686 & 0,681 & 0,432 & 0,426 \\
\hline
\end{tabular}




\section{DISCUSSION}

The main purpose of this exercise is not to provide exact numbers on the reduction of pollination potential in the landscape due to urban development. Rather, it is an attempt to quantitatively show, through a series of relatively straightforward, fairly simple calculations, that the effect of response diversity within a functional group potentially matters and should be taken into account when making decisions about landscape management and the maintenance of resilience from a food security/ pollination perspective. The 4.4 times larger impact from land use change in the amplified scenario compared to the more moderate land use change scenario for solitary bees as compared to the lumped functional group is striking. Thus, if the solitary bee group is not analyzed separately, the amplification of the reduction in pollinator potential under more intense land use change scenarios will be underestimated and there is a risk that this subfunctional group will be lost in the process of urban development. Our results also show that urban development, articulated through land use change, will directly affect the pollination potential of the landscape in Stockholm County. The decreases, however, are minor in this study, indicating that future land use change, in the form of the present development plan, does not pose a major threat to pollination potential in this context. The effect is still there and may have a larger impact in areas with a larger decrease in semi-natural habitats. The solitary bees do react more negatively to the land use changes when analyzed separately than when lumped together with the other bees in the functional group, but the decrease is still moderate. The assumptions upon which these calculations are based are simplified in that they do not take into account complex interactions such as competition among pollinators for resources and among plants for pollinators (Kremen et al. 2007), or large-scale landscape connectivity. The quality, quantity, and spatial location of resources will also influence the ability of a pollinator group to persist in the landscape (Bodin et al. 2006). The correlations upon which these estimates are based do, however, suggest that saturation of pollinators is far from reached in this study area but might become a limiting factor in areas with higher densities of pollinators (Steffan-Dewenter 2003).

The fact that our results show such a distinct relative difference between the solitary bee functional group and the lumped functional group between the two levels of the RUDP scenario, while the ecosystem services of pollination and crop production are practically unchanged, shows the importance of assessing resilience in a landscape. If our goal is to maintain the flow of ecosystem services over time in a landscape that is subject to change, it is not adequate to estimate the effect of change on the ecosystem services flow based on the parts of biodiversity that are presently the main contributors. Research shows that the relative importance of those contributors may indeed change in the face of land use change (Chapin 2000) and climate change (Fitzpatrick et al. 2008). It is our belief that the approach of estimating change in resilience by quantifying change in response diversity over time, as presented in this article, can be useful in assessing resilience in urban agricultural landscapes in general. The increasing spatial contact between agricultural and urban areas is a trend that can be seen all over Europe (EEA 2006). This trend suggests that making sustainable trade-offs between alternative land uses and ecosystem services will become even more crucial in the future. The approach is also valid for agricultural landscapes dominated by monocultures, where one crop type, similar to the effect of urbanization, is pushing out the semi-natural areas that are essential for keeping wild pollinators in the landscape.

It is thus our aspiration that our results will contribute to the process of designing tools and methods for calibrating the importance of resilience over space and time, and will thus contribute to safeguarding the ecosystem services flow, whether it would be for building food security or maintaining some other ecosystem services or combinations of those services. However, there is still much to be done to improve our knowledge of the importance of biodiversity in managing social-ecological landscapes for continued ecosystem services flows.

\section{NEXT STEPS}

Although we believe that the 4.4 times larger impact on solitary bees, in its own right, motivates our recommendation of assessing response diversity in a sustainable urban development context, it would also be of interest to quantify how the subsequent reductions would actually impact any future requirements for pollinating bees. This might be done by running a sensitivity analysis to investigate if/where there are thresholds at which a functional group can no longer persist in the landscape. 
Fig. 4. Change in pollination potential under both the moderate and the amplified Regional Urban Development Plan (RUDP) in combination with the non-pollinated crop scenario for both the lumped functional pollinator group and when observing solitary bees and generalists separately.

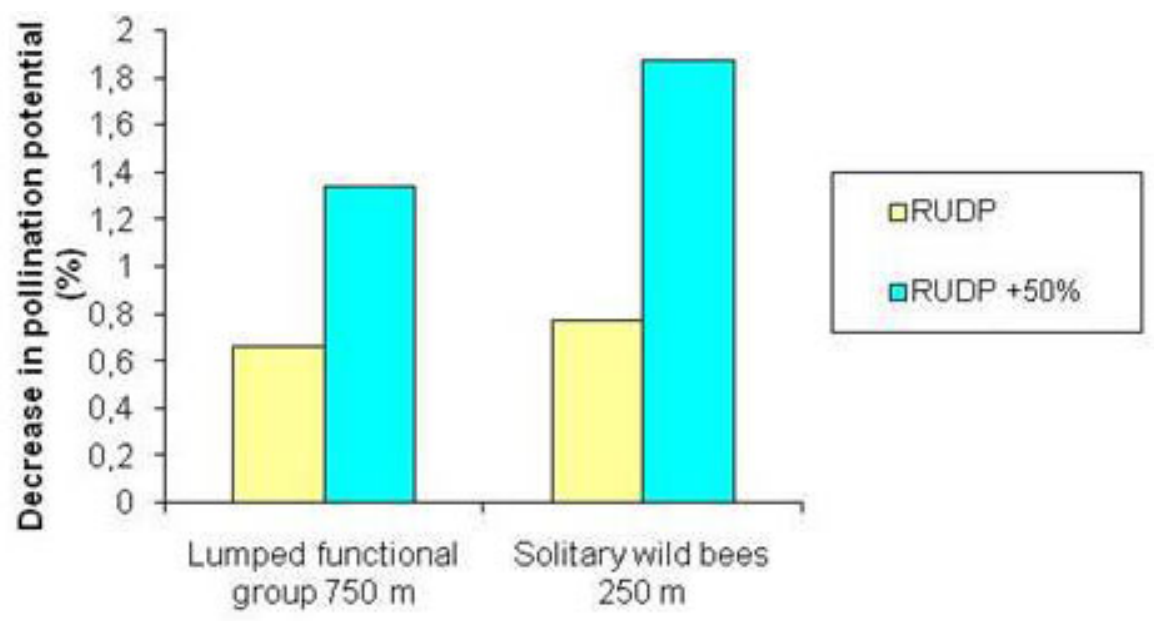

Information on possible thresholds in combination with estimating the risk of losing the major functional group and having the replacement group functioning at a lower rate than before could be a constructive way of taking the results of this paper to a more operationalized level.

\section{Landscape connectivity}

To further operationalize our results, it is necessary to identify how the decrease in pollination potential for both the lumped and the subfunctional group are distributed in the landscape in a connectivity context (Zetterberg 2009). Such information will provide spatial knowledge on where and on what scales in the landscape resilience is being eroded and thus needs to be managed in order to maintain our options of what to grow in the future.

\section{Addressing climate change}

Additional scenarios of change are also vital. Since the pollinators necessary for upholding future options on what to grow depend on the structure of the landscape and interactions with plant food sources, the effects of climate change becomes central. Climate change might not only affect the levels of pollination potential in the landscape by changing the percentage and distribution of semi- natural habitats in the landscape, but may also affect the synchrony of pollination between plants and pollinators (Earthwatch 2006). Since crops alone do not sustain the pollination potential, disruptions with complementary wild flora food sources also need to be assessed in the context of managing food security, especially when non-pollinated crops are grown, as in the NPC scenario.

\section{Economic value}

Assessing the economic value of resilience as an insurance against the risk of a malfunctioning of the ecosystem and the consequent interruption of the provision of goods and services to humans is also essential. Attempts have been made to address the economic value of functional diversity in the generation of ecosystem services (see e.g., Ricketts et al. 2004, Mäler et al. 2008), but studies addressing the value of resilience are, to a great extent, lacking (although see Mäler et al. 2007). Our results can add to this line of research by providing quantitative spatially explicit information on the change of resilience in the landscape, the quantitative, spatial connection to ecosystem services generation, and the risk of reduced option values associated with these changes in the context of building food security in the landscape over time. 


\section{CONCLUSIONS}

The importance of resilience for maintaining a steady flow of ecosystem services from a landscape over time is recognized, but the empirical backing is still, to a great extent, lacking. In this paper, we show the value of assessing the role of biodiversity in the generation of ecosystem services in a landscape through the lens of functional groups and response diversity, and that the differences in scale of operation within a functional group can be useful in this context. We also emphasize the importance of constructing conceivable scenarios for assessing resilience in a social-ecological system over time, since the role of response diversity in building resilience is only manifested in the light of change. Projections of change in large-scale socioeconomic drivers in combination with rigorous quantitative, spatially explicit, ecologically based assessment is constructive for operationalizing our knowledge of the connections between biodiversity and the generation and value of ecosystem services and sustainable management of social-ecological systems over time.

Responses to this article can be read online at: http://www.ecologyandsociety.org/voll5/iss3/art20/ responses/

\section{Acknowledgments:}

We would like to thank the Swedish Research Councilfor Environment, Agricultural Sciences and Spatial Planning (FORMAS) for funding, through the Center of Excellence. We would also like to thank two anonymous reviewers for insightful comments.

\section{LITERATURE CITED}

Allen-Wardell, G., P. Bernhardt, R. Bitner, A. Burquez, S. Buchmann, J. Cane, P. A. Cox, V. Dalton, P. Feinsinger, M. Ingram, D. Inouye, C. E. Jones, K. Kennedy, P. Kevan, H. Koopowitz, R. Medellin, S. Medellin-Morales, G. P. Nabhan, B. Pavlik, V. Tepedino, P. Torchio, and S. Walker. 1998. The potential consequences of pollinator declines in the conservation of biodiversity and stability of food crop fields. Conservation Biology 12:1-11.
Ashebir, D., M. Pasquini, and W. Bihon. 2007. Urban agriculture in Mekelle, Tigray state, Ethiopia: Principal characteristics, opportunities and constraints for further research and development. Cities 24(3):218-228.

Balmford, A., A. Bruner, P. Cooper, R. Costanza, S. Farber, R. E. Green, M. Jenkins, P. Jefferiss, V. Jessamy, J. Madden, K. Munro, N. Myers, S. Naeem, J. Paavola, M. Rayment, S. Rosendo, J. Roughgarden, K. Trumper, and R. K. Turner. 2002. Economic reasons for conserving wild nature. Science 297:950-953.

Balvanera, P., A. B. Pfisterer, N. Buchmann, J. S. He, T. Nakashizuka, D. Raffaelli, and B. Schmid. 2006. Quantifying the evidence for biodiversity effects on ecosystem functioning and services. Ecology Letters 9:1146-1156.

Berkes, F., and C. Folke, editors. 1998. Linking social and ecological systems. Cambridge University Press, Cambridge, UK.

Bodin, Ö., M. Tengö, A. Norman, J. Lundberg, and T. Elmqvist. 2006. The value of small size: loss of forest patches and ecological thresholds in southern Madagascar. Ecological Applications 16:440-451.

Chapin, III F. S., E. S. Zavaleta, V. T. Eviner, R. L. Naylor, P. M. Vitousek, H. L. Reynolds, D. U. Hooper, S. Lavorel, O. E. Sala, S. E. Hobbie, M. C. Mack, and S. Diaz. 2000. Consequences of changing biodiversity. Nature 405:234-242.

Corbet, S. A. 2000. Conserving compartments in pollination webs. Conservation Biology 14:12291231.

Costanza, R., L. J. Graumlich, and W. Steffen, editors. 2007. Sustainability or collapse? An integrated history and future of people on earth. Dahlem Workshop Report 96. MIT Press. Cambridge, Massachusetts, USA.

Deutsch, L., C. Folke, and K. Skånberg. 2003. The critical natural capital of ecosystem performance as insurance for human well-being. Ecological Economics 44(2-3):205-217.

Díaz, S., S. Lavorel, F. de Bello, F. Quétier, K. Grigulis, and T. M. Robson. 2007. Incorporating plant functional diversity effects in ecosystem 
service assessments. Proceedings of the National Academy of Sciences, December 26, 104 (52):20684-20689.

Earthwatch Institute. 2006. Climate change threatens pollination timing. ScienceDaily. [online] URL: http://www.sciencedaily.com/releases/2006/0 8/060809234056.htm.

Elmqvist, T., C. Folke, M. Nyström, G. Peterson, J. Bengtsson, B. Walker, and J. Norberg. 2003. Response diversity, ecosystem change, and resilience. Frontiers in Ecology and the Environment 1(9):488-494.

European Environment Agency (EEA). 2006. Urban Sprawl in Europe. EEA Report 10/2006, ISBN 92-9167-887-22. European Environment Agency, Copenhagen, Denmark.

European Spatial Planning Observation Network (ESPON.) 2009. [online] URL: http://www.espon. eu/main/Menu ScientificTools.

FAOSTAT. 2008. [online] URL: http://faostat.fao. org/site/339/default.aspx.

Fitzpatrick, M. C., A. D. Gove, N. J. Sanders, and R. Dunn. 2008. Climate change, plant migration, and range collapse in a global biodiversity hotspot: the Banksia (Proteaceae) of Western Australia. Global Change Biology 14:1337-1352.

Food and Agriculture Organization (FAO). 2008. The state of food insecurity in the world 2008. High food prices and food insecurity-threats and opportunities. Food and Agriculture Organization of the United Nations. Viale delle Terme di Caracalla, Rome, Italy.

Gange, A. C., and D. E. Lindsay. 2002. Can golf courses enhance local biodiversity? Pages 721-736 in $\mathrm{E}$. Thain, editor. Science and golf IV. Routledge, London, UK.

Hooper, D. U., F. S. Chapin, J. J. Ewel, A. Hector, P. Inchausti, S. Laovorel, J. H. Lawton, D. M. Lodge, M. Loreau, S. Naeem, B. Schmid, H. Setala, A. J. Symstad, J. Vandermeer, and D. A. Wardle. 2005. Effects of biodiversity on ecosystem functioning: a consensus of current knowledge. Ecological Monographs 75:3-35.
Huggett, A. J. 2005. The concept and utility of 'ecological thresholds' in biodiversity conservation. Biological Conservation 124:301-310.

Intergovernmental Panel on Climate Change (IPCC). 2007. Climate change impact, adaptation and vulnerability. Working group II contribution to the Intergovernmental Panel on Climate Change fourth assessment report. [online] URL: http://www .ipcc.ch/ipccreports/ar4-wg2.htm.

Klein, A. M., B. E. Vaissiere, J. H. Cane, I. Steffan-Dewenter, S. A. Cunningham, C. Kremen, and T. Tscharntke. 2007. Importance of pollinators in changing landscapes for world crops. Proceedings of the Royal Society of Bees 274:303313.

Kremen, C., N. M. Williams, M. A. Aizen, B. Gemmill-Herren, G. LeBuhn, R. Minckley, L. Packer, S. G. Potts, T. Roulston, I. SteffanDewenter, D. P. Vazquez, R. Winfree, L. Adams, E. E. Crone, S. S. Greenleaf, T. H. Keitt, A. M. Klein, J. Regetz, and T. H. Ricketts. 2007. Pollination and other ecosystem services produced by mobile organisms: a conceptual framework for the effects of land-use change. Ecology Letters 10 (4):299-314.

Mäler, K. G., S. Aniyar, and Å. Jansson. 2008. Accounting for ecosystem services as a way to understand the requirements for sustainable development. Proceedings of the National Academy of Sciences 105:9501-9506.

Mäler, K. G., C. Z. Li, and G. Destouni. 2007. Pricing resilience in a dynamic economyenvironment system: a capital-theoretical approach. Beijer Discussion Papers No. 208.

McDonald, R. 2008. Global urbanization: Can ecologists identify a sustainable way forward? Frontiers in Ecology and the Environment 6(2):99104.

National Research Council (NRC). 2005. Valuing ecosystems services: toward better environmental decision making. National Academies Press, Washington, D.C., USA.

Nyström, M. 2006. Redundancy and response diversity of functional groups: implications for the resilience of coral reefs. Ambio 35(1):30-35. 
Pettesson, M., B. Cederberg, and A. Nilsson. 2004. Crops and wild bees in Sweden (In Swedish). Swedish wild bee project at Artdatabanken, Swedish University of Agriculture and the Department of Plant Ecolology, Uppsala University, Uppsala, Sweden.

Ricketts, T. H., G. C. Daily, P. R. Ehrlich, and C. Michener. 2004. Economic value of tropical forest to coffe production. Proceedings of the National Academpy of Sciences 101:12579-12582.

Rockström, J., W. Steffen, K. Noone, Å. Persson, S. F. III. Chapin, E. F. Lambin, T. M. Lenton, M. Scheffer, C. Folke, H. J. Schellnhuber, B. Nykvist, C. A. de Wit, T. Hughes, S. van der Leeuw, H. Rodhe, S. Sörlin, P. K. Snyder, R. Costanza, U. Svedin, M. Falkenmark, L. Karlberg, R. W. Corell, V. J. Fabry, J. Hansen, B. Walker, D. Liverman, K. Richardson, P. Crutzen, and J. A. Foley. 2009. A safe operating space for humanity. Nature 461:472-475.

RUFS. 2001. Regional Development Plan for Stockholm County. Office of Regional Planning and Urban Transportation. Stockholm.

RUFS. 2010. [online] URL: http://www.rtk.sll.se.

Sala, O. E., S. F. III. Chapin, J. J. Armesto, E. Berlow, J. Bloomfield, R. Dirzo, E. HuberSanwald, L. F. Huenneke, R. Jackson, A. Kinzig, R. Leemans, D. M. Lodge, M. A. Mooney, M. Oesterheld, N. L. Poff, M. T. Sykes, B. H. Walker, M. Walker, and D. H. Wall. 2000. Global biodiversity scenarios for the year 2100. Science 287:1770-1774.

Saskatchewan Canola Development Commission (SCDC). 2008. [online] URL: http://www.saskcano la.com/.

Scheffer, M., S. Carpenter, J. Foley, C. Folke, and B. Walker. 2001. Catastrophic shifts in ecosystems. Nature 413:591-596.

Smith, J. 1996. Urban agriculture: progress and prospect:1975-2005. Cities feeding people Report 18. International Development Research Centre, Ottawa, Ontario, Canada.

Steffan-Dewenter, I. 2003. Seed set of male-sterile and male-fertile oilseed rape (Brassica napus) in relation to pollinator density. Apidologie 34:227235.

Steffan-Dewenter, I., U. Münzenberg, C. Bürger, C. Thiers, and T. Tschrntke. 2002. Scaledependent effects of landscape context on three pollinator guilds. Ecology 83(5):1421-1432.

Svenska Raps. 2007. Location of oil rape seed fields in Stocholm County 2006. [online] URL: htt p://www.svenskraps.se.

Swedish CORINE. 2006. Lantmäteriet. Database on land use and vegetation (GSD-Marktäckedata). [online]URL: http://www.lantmateriet.se/templates/ LMV Page.aspx?id=1037.

United Nations (UN). 2008. Millenium development goals. [online] URL: http://www.un.org/millennium goals/.

Walker, B. 1992. Biodiversity and ecological redundancy. Conservation Biology 6:18-23.

Walker, B. H., J. M. Anderies, A. P. Kinzig, and P. Ryan. 2006. Exploring resilience in socialecological systems: comparative studies and theory development. CSIRO Publishing, Australia.

Walter-Hellwig, K., and R. Frankl. 2000. Foraging habitats and foraging distances of bumblebees, Bombus ssp. (Hym. Apidae), in an agricultural landscape. Journal of Applied Entomology 124:299-306.

Westphal, C., I. Steffan-Dewenter, and T. Tscharntke. 2003. Mass flowering crops enhance pollinator densities at a landscape scale. Ecology Letters 6:961-965.

World Resource Institute (WRI). 2005. Ecosystems and human well being: biodiversity synthesis. World Resource Institute, Washington, D.C., USA.

Zetterberg, A. 2009. Network based tools and indicators for landscape ecological assessments, planning, and design. Licentiate thesis in Land and Water Resources Engineering Stockholm, Sweden. KTH-Environmental Management and Assessment Research Group Department of Land and Water Resources Engineering Royal Institute of Technology, Stockholm, Sweden. ISBN 978-91-7415-249-4. 